\title{
Suitability of base liquid in a nanofluid-laden solar flat-plate collector with emphasize on bio- glycol
}

\author{
Seyed Reza Shamshirgaran ${ }^{1,2}$, Hussain H. Al-Kayiem ${ }^{1 *}$, Morteza K. Assadi ${ }^{1}$ and K.V. \\ Sharma ${ }^{3}$ \\ ${ }^{1}$ Solar Thermal Advanced Research Center (STARC), Universiti Teknologi PETRONAS, 32610 \\ Bandar Seri Iskandar, Malaysia \\ ${ }^{2}$ Department of Mechanical and Energy Engineering, Shahid Beheshti University, 16765-1719, \\ Tehran, Iran \\ ${ }^{3}$ Centre for Energy Studies, Department of Mechanical Engineering, JNTUH College of Engineering, \\ Kukatpally, Hyderabad 500085, India
}

\begin{abstract}
Ethylene glycol and propylene glycol are commonly used as thermal liquids in solar flat-plate collectors (FPCs). They are utilized as base liquid as well as for improving the stability of nanofluids in FPCs. The objective of the present paper is to introduce a renewable-derived bio glycol for use as base liquid in FPCs. The effect of base ratio (BR) of different glycol products on the performance of a conventional FPC and a nanofluidladen FPC is investigated in this paper to determine its suitability. MATLAB programming was employed for modeling the performance of the FPC operating with copper and cerium oxide nanomaterials. The results show that 20:80 bio glycol/water mixture is capable of enhancing the FPC's energetic efficiency up to $72.1 \%$ which is higher than with either ethylene glycol and propylene glycol. The energy efficiency of a glycol-based nanofluid-filled FPC decreases with the base ratio of all three glycol products. Since bio glycol is a non-toxic and safe product, it can be utilized as a safe and environmentally-friend antifreeze and base liquid in nanofluid-filled FPCs.
\end{abstract}

\section{Introduction}

Nanomaterials can mix with an appropriate base liquid viz., water, ethylene glycol (EG), propylene glycol (PG), oil etc. to extract more solar energy while flowing in the collector of solar water heaters. Many researchers have attempted to improve the performance of FPCs by using water-based and non-water-based nanofluids in recent years. [1] carried out a numerical study on the performance of an alumina-water nanofluid. The study revealed that the collector's outlet temperature would increase by $7.20 \%$ compared to water. [2] introduced the effect of water/cerium oxide nanofluid on the performance of a FPC. The zero-loss efficiency of the collector increased by $10.74 \%$. Studies by $[3,4]$ demonstrated a significant enhancement in the performance of a FPC using by $\mathrm{EG} / \mathrm{SiO}_{2}$ and $\mathrm{EG} / \mathrm{CuO}$ nanofluids. The second-law analysis by [5] for an EG/silica nanofluid-filled FPC showed that there would be

\footnotetext{
${ }^{*}$ Corresponding author : hussain_kayiem@utp.edu.my
} 
a boosting in the exergy efficiency of the FPC. [6] measured the thermo-physical properties of $\mathrm{BG} / \mathrm{Al}_{2} \mathrm{O}_{3}$ mixture and [7] studied the heat transfer behaviour of $\mathrm{BG} / \mathrm{TiO}_{2}$ nanofluid. Both EG and PG are chemically-derived products. Moreover, EG is a toxic and non-environmental safe product. PG is non-toxic, but it may increase the risk of plumbing in a collector system. To tackle the issues with EG and PG products and have a positive effect on the sustainability development, the bio glycol (BG) proposed for utilization as an additive base liquid in the current investigation. BG inherits non-reactive properties of alcohol family yet exhibit nontoxic plant-based properties which have better thermo-physical properties as compared to ethylene glycol-based working fluid. Therefore, the aim of this study is to substitute fossilfuel-based glycols with renewable-derived biofuel glycol which is more safe and environmental-friendly to provide higher sustainability of solar flat-plate collectors.

The current reported literature shows that although, there have been research studies undertaken using different nanofluids, the bio fluids have not yet been studied in the case of FPCs. There has not been any comparison between BG, EG and PG nanofluids as well. The suitability of base liquid in terms of performance and environmental aspects is very crucial to investigate. Therefore, the objective of this research is directed to study the effect of these base liquids on the overall performance of a nanofluid-laden FPC at different base ratios (BRs).

\section{Methodology}

The study has been accomplished by using mathematical modeling in MATLAB to reflect the behavior of a FPC. The glazing cover of a FPC receives the solar insolation and passes it toward the absorber plate. The thermal energy of the absorber plate is then transferred to the working fluid flowing inside the riser tubes. The collector's specifications for the current investigation are mainly adapted from the $G$-series product data of Thermo Dynamics Ltd. (for details see [8]). The dimensions, riser diameter, optical efficiency and solar irradiation are $2.5 \mathrm{~m} \times 1.2 \mathrm{~m}, 7 \mathrm{~mm}, 85 \%$ and $808 \mathrm{~W} / \mathrm{m}^{2}$. Here, the investigation is focused on the first-law and second-law efficiency of the FPC operating with different working fluids including pure water, BG, PG, and EG and also their mixture with nanoparticles. It is assumed that the flow inside the FPC is under steady state and laminar condition. The instantaneous performance of the FPC is evaluated when filled with aforementioned working fluids.

\section{Evaluation of Nanofluid Thermo-Physical Properties}

Thermo-physical properties of nanofluids and base fluids are calculated to obtain the thermal conductivity $(k)$, heat capacity $\left(C_{p}\right)$, density $(\rho)$ and viscosity $(\mu)$ corresponding to the change in volume fraction $(\phi)$ of the mixture. The correlations are given in Table 1. In these equations $\kappa_{B}=1.381 \times 10^{-23} \mathrm{~J} / \mathrm{K}$ is the Boltzmann constant and $d_{p}$ represents the nanoparticle size. The subscriptions $b f, p$, and $n f$ denote base fluid, nanoparticle, and nanofluid, respectively.

\section{Analysis for 1st Law of Thermodynamics}

The analysis of first-law efficiency of a conventional FPC involves certain iterations for determining the fluid's outlet temperature, absorber plate's mean temperature and the other relevant parameters. Details of these processes may be found in [9] and [10]. However, the equation used for the estimation of energy absorbed by the FPC is given as:

$$
Q_{u}=A_{c}\left[S-U_{L}\left(T_{p m}-T_{a}\right)\right]
$$

where $A_{c}$ is the collector surface area, $S=\left(\tau_{g} . \alpha_{p}\right) G_{t}$ is the effective radiation received by the 
collector in which $\tau_{g}, \alpha_{p}$, and $G_{t}$ are glass transmittance, plate absorptance and solar irradiation, respectively. Parameter $T_{a}$ stands for the ambient air temperature, $U_{L}$ and $T_{p m}$ represent the collector heat loss coefficient and absorber plate's mean temperature which would be determined. The amount of useful absorbed energy is used for the analysis of first law or energetic efficiency:

$$
\eta_{\text {eng }}=\frac{Q_{u}}{A_{c} G_{t}} \times 100
$$

The outlet temperature can be computed at a given value of water inlet temperature $\left(T_{i n}\right)$, fluid mas flow rate $(\dot{m})$ and its heat capacity as follows:

$$
T_{\text {out }}=T_{\text {in }}+Q_{u} / \dot{m} C_{p}
$$

Table 1. The correlations for prediction of the nanofluid properties

\begin{tabular}{|l|l|l|}
\hline Property & Model & Correlation \\
\hline Mass density & $\begin{array}{l}\text { Principle of } \\
\text { mixtures }\end{array}$ & $\rho_{n f}=\phi \rho_{p}+(1-\phi) \rho_{b f}$ \\
\hline Specific heat & $\begin{array}{l}\text { Thermal } \\
\text { equilibrium }\end{array}$ & $C_{p, n f}=\frac{\phi(\rho C)_{p}+(1-\phi)(\rho C)_{b f}}{\rho_{n f}}$ \\
\hline $\begin{array}{l}\text { Thermal } \\
\text { conductivity }\end{array}$ & Xuan & $\frac{k_{n f}}{k_{b f}}=\frac{k_{p}+2 k_{b f}-2 \phi\left(k_{b f}-k_{p}\right)}{k_{p}+2 k_{b f}+\phi\left(k_{b f}-k_{p}\right)}+\frac{\rho_{p} \phi C_{p}}{2 k_{b f}} \sqrt{\frac{2 \kappa_{B} T}{3 \pi d_{p} \mu_{b f}}}$ \\
\hline $\begin{array}{l}\text { Dynamic } \\
\text { viscosity }\end{array}$ & Brinkman & $\frac{\mu_{n f}}{\mu_{b f}}=\frac{1}{(1-\phi)^{2.5}}$ \\
\hline
\end{tabular}

Determining the value of fluid outlet temperature and plate mean temperature is necessary for the evaluation of second law efficiency of the FPC.

\section{Analysis for 2 nd Law of Thermodynamics}

Exergetic efficiency explains the amount of entropy generation due to solar radiation absorption/emission, losses to the surrounding, heat conduction from the plate to the working fluid and finally, due to the linear pressure drop in the collector manifolds, risers and fittings. The exergy efficiency of a FPC is calculated using the following equation [11]:

$$
\eta_{\text {ex }}=\dot{m}\left[C_{p}\left(T_{\text {out }}-T_{\text {in }}-T_{a} \operatorname{Ln}\left(T_{\text {out }} / T_{\text {in }}\right)-\Delta p / \rho\right] /\left(G_{t} A_{c} \eta_{\max , s}\right)\right.
$$

where $\eta_{\operatorname{maxs}}$ is called the exergy factor of solar incident, obtained from the Badescu model approximation [11] given by:

$$
\eta_{\max , s}=1-(4 / 3)\left(T_{a} / T_{s}\right)+(1 / 3)\left(\varepsilon / f_{s}\right)\left(T_{a} / T_{s}\right)^{4} ; \quad\left(f_{s} / \varepsilon\right) \geq\left(T_{a} / T_{s}\right)^{3}
$$

in which $\varepsilon$ and $f_{s}$ denote the emittance of the collector absorber plate and geometry factor of the Sun, respectively. The value of $f_{s}$ for an isotropic radiation from the Sun is around $2.176 \times 10^{-5}[12]$. The pressure loss across the collector is approximated as:

$$
\begin{gathered}
\Delta p=\left[f \frac{L}{D}\left(\rho_{n f} \frac{V^{2}}{2}\right)\right]_{\text {in / out header }}+\left[\rho_{n f} g\left(L \sin \beta+h_{L}\right)\right]_{\text {riser }+ \text { fitting }} \\
h_{L}=\frac{8 \dot{m}_{\text {riser }}^{2}}{\rho_{n f} g \pi^{2} D_{i}^{4}}\left(f \frac{L}{D_{i}}+\sum K_{L}\right)
\end{gathered}
$$


where $f$ and $K_{L}=2$ refer to the friction factor and coefficient loss for the laminar flow, and $L$ and $D_{i}$ are the length and internal diameter of riser tubes.

\section{Results and Discussions}

Two nanomaterials, i.e. coper and cerium oxide, with the size of $25 \mathrm{~nm}$ and concentration of $4 \%$ were considered for the present study. The values for the ambient temperature, temperature difference between ambient and collector inlet, and the velocity of working flow in the header were set as $301 \mathrm{~K}, 2 \mathrm{~K}$, and $0.3 \mathrm{~m} / \mathrm{s}$, respectively.

\subsection{Effect of base liquid as antifreeze}

In order to prevent freezing during the operation of FPCs in cold climates, antifreeze is required. There are two commonly used antifreeze viz. EG and PG in FPCs. The new antifreeze, i.e. BG, as a renewable-derived product is compared with EG and PG to study its effect on the performance of a FPC. It should be noted that the temperature-dependent correlations for thermo-physical properties of the EG and PG is retrieved from the available data in ASHRAE fundamental handbook [13] whereas the data for BG is adapted from the supplier of the heat transfer fluid, namely Dynalene Inc. [14]. In fact, the variations of thermo-physical properties of these glycol products versus the temperature are modeled using curve-fitting tool in MATLAB and then used in the simulation. It is also necessary to mention that the BG20, for instance, stands for the ratio of 20:80 for BG:water mixture.

Figure 1 shows that the energetic efficiency of a FPC decreased with the increase in antifreeze concentration. BG had the highest energetic efficiency at $20 \%$ to $40 \%$ volume percentage but EG had the highest energetic efficiency after $40 \%$ volume percentage. Therefore, $\mathrm{BG}$ is preferable to be used as an antifreeze in low concentrations as compared to EG and PG. The lowest efficiency at each concentration is associated with PG product. It is also seen from the graph that water provided the highest energetic efficiency in comparison with different antifreezes.

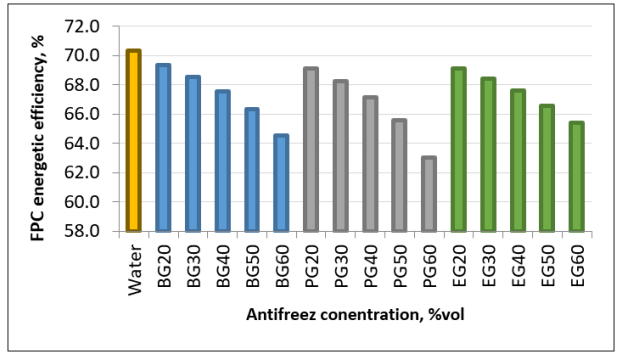

Fig. 1. Energetic efficiency of a FPC vs the concentration of glycol-based antifreezes

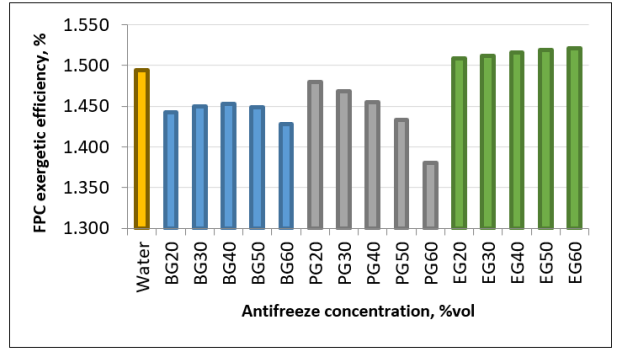

Fig. 2. Exergetic efficiency of a FPC vs the concentration of glycol-based antifreezes

The exergetic efficiency of the FPC when using different antifreezes is depicted versus the mixture's concentration in Figure 2. As it is observed, the exergetic efficiency decreases with the increase of concentration for PG but improves for EG at increasing concentration percent. FPC's exergetic efficiency remains rather stable with different volume percentages of BG. Meanwhile, the exergy efficiency of a FPC using pure water decreases when BG and PG is used but increases with the addition of EG as antifreeze in the working fluid. EG causes the highest exergetic efficiency among all three types of glycol-based antifreezes. 


\subsection{Effect of base liquid as nanofluid}

Comparison of different metal and oxide nanoparticles' role in the performance of a FPC demonstrated that copper $(\mathrm{Cu})$ and cerium oxide $\left(\mathrm{CeO}_{2}\right)$ nanomaterials possess the highest capability of improving the performance of the collector [15]. Hence, simulations have been carried out using these nanoparticles mixed with four different base fluids at different base ratios (BRs). In other words, the base fluid consists of pure water, BG/water, EG/water, and $\mathrm{PG} /$ water with the base ratio varying from $20 \%$ to $60 \%$ by volume. The importance of adding nanoparticles into the base fluid is illustrated in Figure 3. At each base ratio, the efficiency has been depicted along with the pure base liquid for better understanding. As shown, the energetic efficiency of the FPC using BG is higher than that of with pure water without nanoparticles. The efficiency of BG20-based copper nanofluid is $71.7 \%$ and ranks the highest compared to EG and PG with the same base ratio and volume fraction.

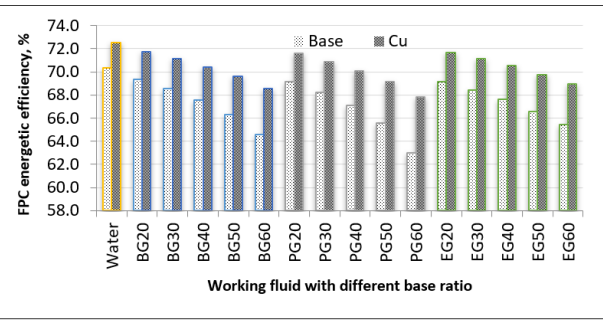

Fig. 3. Energy efficiency of a $\mathrm{Cu}$ nanofluidbased FPC vs. base ratio of glycol products

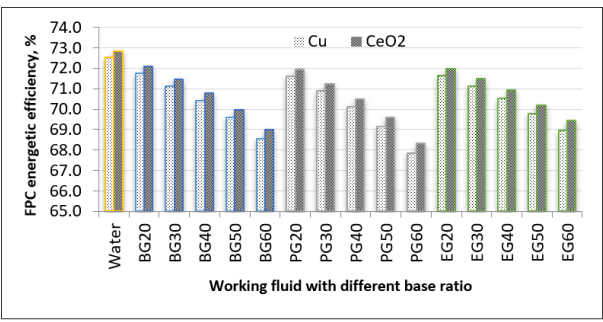

Fig. 4. Energetic efficiency of $\mathrm{Cu}$ and $\mathrm{CeO}_{2}$ nanofluid-filled FPCs at different glycols' BR

The comparison of energetic efficiency between pure $\mathrm{Cu}$ nanofluid and $\mathrm{CeO}_{2}$ nanofluid is shown in Figure 4. The energetic efficiency of the FPC is highest when using $\mathrm{CeO}_{2}$ at every base ratio. Figure 5 displays the exergetic efficiency of a FPC working with $\mathrm{Cu}$ nanofluid mixed with BG, PG, and EG at different base ratios. The efficiency of the FPC with water/EG copper nanofluid is $1.601 \%$ and ranks highest compared to BG and PG.

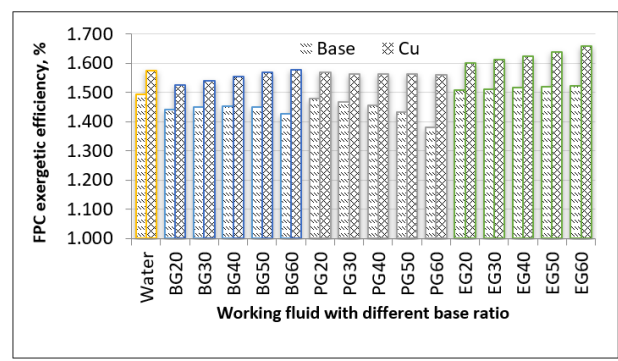

Fig. 5. Exergetic efficiency of a $\mathrm{Cu}$ nanofluidbased FPC vs. base ratio of glycol products

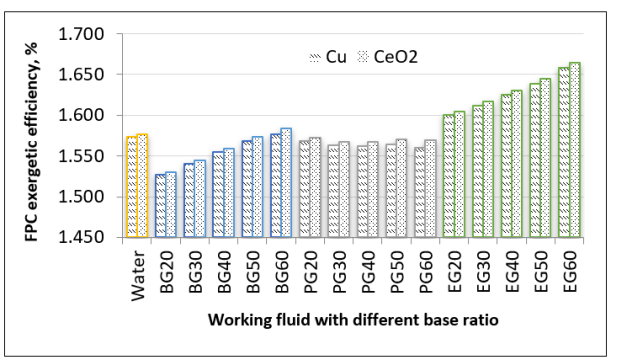

Fig. 6. Exergetic efficiency of $\mathrm{Cu}$ and $\mathrm{CeO}_{2}$ nanofluid-based FPCs at different glycols' BR

Figure 6 presents the comparison of exergetic efficiency between pure $\mathrm{Cu}$ nanofluid- and $\mathrm{CeO}_{2}$ nanofluid-based collector. The exergetic efficiency of the FPC would be the highest when using $\mathrm{CeO}_{2}$ at every base ratio. Therefore, the possible best nanofluid in this case is $\mathrm{EG}+\mathrm{CeO}_{2}$ mixture. It is observed from Figure 5 and Figure 6 that $\mathrm{EG}$ performs even better than water as a base liquid of nanofluids.

\section{Conclusion}

The effect of water mixture ratio for glycol-based antifreeze and base liquid as a working 
fluid in solar FPCs has been studied. The following conclusions could be drawn:

- As an antifreeze, glycol products with higher base ratios decrease the energetic efficiency. BG and EG increase the exergetic efficiency while PG decreases it.

- When using as a base liquid, the energy efficiency of the FPC decreases with the base ratio of the glycol products. In the case of exergy efficiency, the base ratio of BG and EG has an enhancing role in exergy efficiency while PG base ratio doesn't affect the exergy efficiency significantly.

- The highest energetic efficiency is achieved with $\mathrm{BG} 20$-based $\mathrm{CeO}_{2}$ nanofluid as $72.1 \%$, Therefore, the possible best nanofluid for maximum energetic efficiency in this study is $\mathrm{BG} 20+\mathrm{CeO}_{2}$ mixture.

- The highest exergetic efficiency is obtained with EG60-based $\mathrm{CeO}_{2}$ nanofluid as $1.66 \%$ and thus it can be considered as the best, in exergy destruction point of view.

- In total, BG is the most suitable substitution of antifreeze compared to PG and EG as it produces the highest energetic efficiency for FPCs; it is non-toxic and environmental-friendly as well and can be considered as a candidate for influencing sustainable development, positively.

The authors wish to acknowledge the logistic supports given by the Universiti Teknologi PETRONAS and the financial support by Ministry of Higher Education (MOHE) Malaysia to produce and publish the current paper under FRGS/1/2017/STG02/UTP/01/1, CS: 0153AB-L58.

\section{References}

1. A. M. Genc, M. A. Ezan and A. Turgut, Appl. Therm. Eng. 130 (2018).

2. M. A. Sharafeldin and G. Gróf, Energy Convers. Manage. 155 (2018).

3. M. Karami, M. A. Akhavan-Behabadi, M. Raisee Dehkordi and S. Delfani, Sol. Energy Mater. Sol. Cells 144 (2016).

4. W. S. Sarsam, S. N. Kazi and A. Badarudin, Solar Energy 122 (2015).

5. S. Salavati Meibodi, A. Kianifar, O. Mahian and S. Wongwises, J. Therm. Anal. Calorim. 126 (2) (2016).

6. A. M. Khdher, N. A. C. Sidik, W. A. W. Hamzah and R. Mamat, International Communications in Heat and Mass Transfer 73 (2016).

7. M. K. Abdolbaqi, R. Mamat, N. A. C. Sidik, W. H. Azmi and P. Selvakumar, Int. J. Heat Mass Transfer 108 (2017).

8. S. R. Shamshirgaran, M. K. Assadi, H. H. Al-Kayiem and K. V. Sharma, MATEC Web Conf. 131 (2017).

9. J. A. Duffie and W. A. Beckman, Solar engineering of thermal processes, 3rd ed. (Wiley, Hoboken, NJ, 2006).

10. S. A. Kalogirou, in Solar Energy Engineering (Second Edition) (Academic Press, Boston, 2014)

11. S. Shamshirgaran, M. Khalaji Assadi, H. H. Al-Kayiem and K. Viswanatha Sharma, Journal of Solar Energy Engineering 140 (3), 031002-031001-031002-031008 (2018).

12. S. R. Shamshirgaran, M. Khalaji Assadi, V. Badescu and H. H. Al-Kayiem, Energy 160, (2018).

13. American Society of Heating Refrigerating and Air-Conditioning Engineers., 2010 ASHRAE Handbook : Refrigeration, Inch-pound ed. (ASHRAE, Atlanta, GA, 2010).

14. D. Inc., (Dynalene Inc., Whitehall, PA, USA., 2018.

15. S. R. Shamshirgaran, M. K. Assadi, H. H. Al $\square$ Kayiem and K. V. Sharma, Materialwiss. Werkstofftech. 49 (4) (2018). 